\title{
HEALTH CARE PROVIDERS' VIEWS CONCERNING KNOWLEDGE AND PRACTICES OF TRADITIONAL BIRTH ATTENDANTS IN TAJIKISTAN : A QUALITATIVE STUDY
}

\author{
Dilofarid Miskinzod \\ Women's and Gender Studies Program, College of Social and Behavioral Sciences, Northern Arizona \\ University, Flagstaff, Arizona, USA
}

${ }^{*}$ Corresponding author: Dilofarid.Miskinzod@nau.edu

\begin{abstract}
Introduction: This study seeks to explore health care providers' perspectives of the traditional birth attendants' knowledge and practices. Methods: This qualitative study was conducted in 2018 with 16 health care professionals working at various levels of maternal health care system in two purposefully selected research settings, Khorog town and Dushanbe, which have different social, economic and ethnic backgrounds. Semi-structured face-to-face interviews were conducted to gather the data. Duration of interviews ranged from 30-60 min. NVivo software for qualitative research was used to analyse the results. Results: This study has shown that health care workers have extremely negative views of the knowledge and practices of traditional birth attendants. They highlight the lack of adequate knowledge of traditional birth attendants on biomedical aspects of birth, poor skills in infections control and lack of use of clean delivery practices. They also claim that the traditional birth attendants' practices also lead to different complications while they are woefully unprepared to recognize obstetric complications during birth. Conclusion: The study recommends providing a skilled birth attendant in every area. It also recommends avoiding a homogeneous approach to address maternal health issues in diverse countries of the Global South and reviewing maternal health care policies and programs to provide the most marginalized groups of women with skilled birth services to improve their maternal health and further decrease maternal mortality in Tajikistan.
\end{abstract}

Keywords: Traditional birth attendant, unsafe practices, home birth, Tajikistan 


\section{Introduction}

Before the emergence of modern obstetric services, traditional birth attendants (TBAs) had been providing obstetric services to women during pregnancy, childbirth and after the birth for a long period of time (Aziato \& Omenyo, 2018). They have historically been the main caregivers for women during delivery. The World Health Organization [WHO] (1992) defines a TBA as "a person who assists a mother during childbirth and who initially acquired her skills by delivering babies herself or through apprenticeship to other traditional birth attendants" (p. 18). Thus, TBAs comprise of individuals who help women during childbirth, but unlike skilled birth attendants (SBAs) (nurses, doctors, midwives) who have training in the obstetric skills and services vital to assisting normal deliveries, TBAs learn to deliver babies through apprenticeships, attain their skills by delivering babies themselves (Patzer, 2008; Pyone et al., 2014) or observations made during deliveries (Pfeiffer \& Mwaipopo, 2013). In a study in Ghana, most TBAs received apprenticeship from close relatives including mothers (Aziato \& Omenyo, 2018; Pfeiffer \& Mwaipopo, 2013). The TBAs learn on the job and therefore may not take advantage of scientific and standard practices of delivery (Aziato \& Omenyo, 2018). Strictly speaking, "the term TBA only refers to traditional, independent (of the health system), informally trained and community-based providers of care during pregnancy, childbirth, and postnatal period" (Pfeiffer \& Mwaipopo, 2013, p. 55).

One of the key benefits of TBAs for women in the local community is their proximity (Gurara et al., 2019). This is especially important in remote and rural areas where access to primary and secondary health care facilities is difficult because of lack of transportation and its high cost, and other financial, social, and economic reasons (Aziato \& Omenyo, 2018; Pyone et al., 2014). They are not paid in cash for the obstetric skills and services they provide to women in the rural areas (Pyone et al., 2014), but are paid in kind (Pfeiffer \& Mwaipopo, 2013; Pyone et al., 2014). These aspects of the nature of the work of the TBAs are considered as strengths that the official health care system has tried to leverage (Pyone et al., 2014). Unfortunately, TBAs are also often accountable for implementing possibly unsafe cultural practices or for delaying and not seeking specialized medical assistance in case of emergency obstetric complications (Chi \& Urdal, 2018; Gurara et al., 2019, Lane \& Garrod, 2016). They have been also criticized for unsafe practices including lack of hygiene during delivery practices and mismanagement of complications (Aziato \& Omenyo, 2018; Chi \& Urdal, 2018; Pfeiffer \& Mwaipopo, 2013). There have been concerns regarding transmission of HIV between the TBAs and the women they help due to lack of use of infection control measures (Aziato \& Omenyo, 2018; Chi \& Urdal, 2018; Pfeiffer \& Mwaipopo, 2013).

The opinion regarding TBAs throughout the globe has been changing over last years (Gurara et al., 2019). The WHO and partners such as other agencies of the United Nations initially promoted the use of TBAs during home births if they had received adequate training (Choguya, 2014; Gurara et al., 2019). These organizations promoted it as a global public health strategy to decrease maternal mortality (Choguya, 2014). Therefore, from 1970s until the early 1990s, training of TBAs was considered as an important intervention to decrease the high maternal and infant mortality and morbidity rates (Gurara et al., 2019). This strategy was accepted and implemented in more than seventy countries of the Global 
South which suffered from the lack of SBAs (Gurara et al., 2019). Nevertheless, the program was reformed and revised in the late 1990s due to evidence demonstrating little impact of TBAs' training on the decrease of maternal mortality without the help of SBAs from healthcare institutions (Gurara et al., 2019). As a result, TBAs were essentially disregarded throughout the 1990s. Instead, based on numerous studies, the global health community recommended that TBA training was cost ineffective and had little influence (Hobday et al., 2018). These studies concluded that the training of TBAs seems to have had minimum impact on maternal mortality in the countries of the Global South. Thus, it was suggested to replace this strategy by a new strategy under which more professional midwives were to be trained (Choguya, 2014; Hernandez et al., 2017; Walraven \& Weeks, 1999).

After the global evidence showed the ineffectiveness of TBAs training, the new WHO guidelines on TBAs' practices recommend rendering companionship and assistance during pregnancy and delivery, in addition to health promotion as the most appropriate way in which the TBA skills are to be employed (Pyone et al., 2014; Thatte et al., 2009). This is a complete shift from the previous scope of TBA training which sought to prepare them to identify mothers and newborns at high risk, to deliver low-risk women safely at home, and to refer women with risk or with diagnosed obstetric complications to a medical institution (Pyone et al., 2014). Under this new strategy, TBAs receive training and orientation to be able to practice as health promoters and birth companions, instead of their traditional role of delivering women at home and referring women to a medical institution only when they develop complications (Pyone et al., 2014). Therefore, TBAs were educated as "health promoters" and "birth companions" and were connected with certain health care facilities (Pyone et al., 2014, p. 41). Their training comprised of a focus on the importance of antenatal care, recognizing the dangers of a home birth, and the advantages of a birth at a medical institution (Pyone et al., 2014).

The main research question guiding the current research is: How do health care professionals perceive the knowledge and practices of TBAs in Tajikistan? The existing literature on TBAs provides some valuable information on the knowledge and practices of TBAs from various research settings around the world. However, there is a paucity of information regarding the perspectives of health care providers about the knowledge and practices of TBAs. Therefore, this study provides additional insight on the subject of TBA from this important angle, because most previous studies have inadequately explored the viewpoints of health professionals by mainly focusing on the standpoints of TBAs regarding their own practices.

\section{Changes in a Birthplace and Care in Tajikistan and their Impacts}

During the Soviet period, Tajikistan similar to other soviet republics benefited from the Soviet system of free and universal health care system (Falkingham, 2003; Habibov \& Fan, 2008; Wiegers et al., 2010). The rate of the utilization of health care was high and there was a negligible difference in its usage among different groups of population. During the Soviet period, pregnant women received comprehensive antenatal care in a health facility, and most births took place in maternity wards 
(Falkingham, 2003). As a result, most women had their deliveries attended by midwives and obstetricians (Falkingham, 2003). The utilization of maternal health care services, including health care institutions for birth, has decreased dramatically since independence resulting in an increasing home birth rate and, a significant rise in the number of women giving delivery at home without a SBA (Falkingham, 2003; Wiegers et al., 2010). With the dissolution of the Union of Soviet Socialist Republics [USSR] the universal free-of-charge health care system has fragmented. In addition, Civil War resulted in a long and deep economic recession that has negatively impacted the healthcare system in Tajikistan (Balabanova et al., 2004; Wiegers et al., 2010). After the independence, poor families could not afford even a trip to the hospital due to the increasing costs (Falkingham, 2003). Changes in the setting of delivery and the individual providing assistance, where a clear shift was observed from giving birth in a medical setting with SBA towards giving birth at home without skilled attendance. The maternal health survey undertaken in Karategin valley by Medecins Sans Frontieres indicated that $83 \%$ of women delivered at home and $63 \%$ of all women delivered with TBAs being present (Skinnider, 2000). These changes also resulted in an increase in maternal mortality rate [MMR] in Tajikistan.

However, with the improvement of socio-economic situation and life and the reduction of poverty rate in the country, a reverse shift happened again. The Demographic and Health Survey [DHS] conducted in Tajikistan in 2012 showed that $77 \%$ of women delivered their babies at a medical institution and $23 \%$ at home (Statistical Agency under the President of the Republic of Tajikistan [SAPRT], the Ministry of Health of the Republic of Tajikistan [MHRT] \& ICF International, 2013). A recent study shows that health care providers argue that most urban and many rural women give births in health care facilities again (Miskinzod, 2020). As a result, MMR decreased in the country.

Maternal health outcomes' trend shows that the type of obstetric services which Tajik women receive impacts their maternal health. The MMR for USSR (Tajikistan was a part of USSR until 1991and there is no data on MMR for Tajikistan alone) was 43 per 100,000 live births in 1988 (Baranov, 1991). MMR was at 68 deaths per 100,000 live births in 1990. It then significantly increased to 120 in 1995 and then dramatically decreased to 85 in 2000 and further to 59 in 2005 and approached 44 deaths per 100,000 live births in 2013 (WHO, 2014) (Figure 1). The MMR was at 17 per 100,000 live births in 2017 (Republican Medical Statistical Center under the Ministry of Health and Social Protection of the Republic of Tajikistan [RMSC], 2018). The data show that MMR worsened dramatically following the collapse of the USSR and the Civil War. It was also time that more women did not receive antenatal care and gave birth to their babies at home without skilled attendance. It then stabilized by 2005 when the government with donor support implemented several interventions in the health care sector. With more women giving birth at a health care facility and with the improvement of antenatal care, MMR decreased (Miskinzod, 2020). 


\section{0}

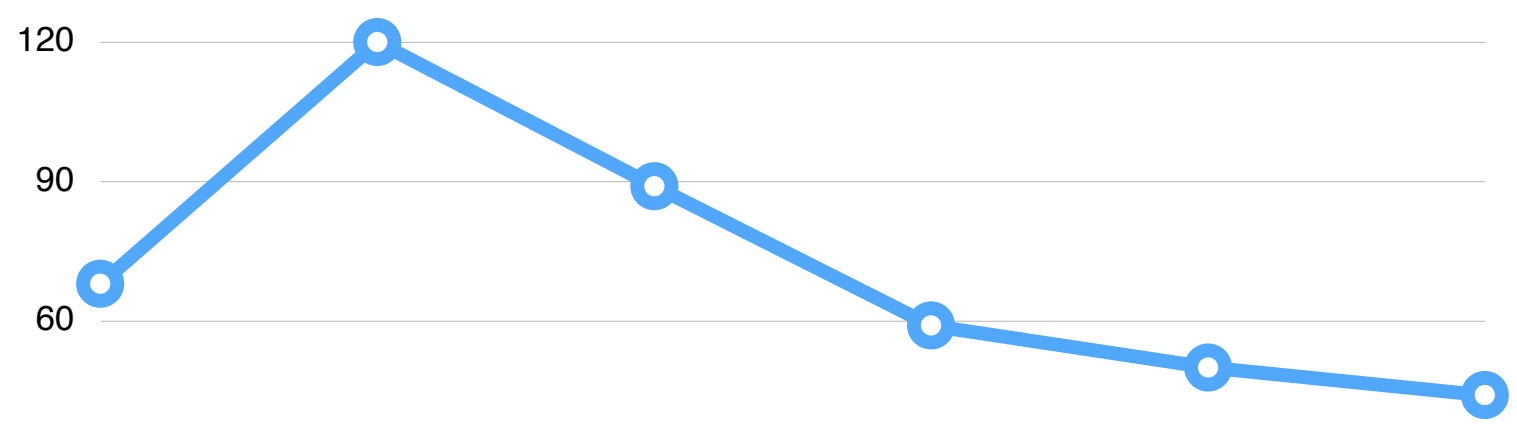

30

$\begin{array}{llllll}0 & 1995 & 2000 & 2005 & 2010 & 2013\end{array}$

Figure 1: Trends in maternal mortality rate from 1990 to 2013 in Tajikistan

\section{Methods}

Sample selection

To understand health care workers' perspectives regarding the knowledge and practices of TBAs and their impact on maternal health in Tajikistan, I used qualitative research method with social constructivist and critical interpretive approaches. The only eligibility criterium was work experience with women during pregnancy, delivery, and postnatal period. Health care professionals were from different layers of maternal health care system, such as maternity hospitals, reproductive health centers and a private clinic. Study respondents were doctors of obstetricians and gynecologists. The respondents were quite homogeneous in terms of their education background. The mean work experience of study participants was 31 years. In-depth semi-structured interviews were conducted with sixteen purposefully selected health care professionals. The study was conducted in two purposefully selected research settings, Khorog town and Dushanbe city, which represent people with different social, economic, and ethnic backgrounds. 
Data collection

An in-depth, semi-structured, problem-centered individual interviews were conducted with health care providers to collect data. An interview guide based on prior literature included questions about the knowledge and practices of TBAs. The interviews were conducted in Shugni, Tajik, and Russian depending on respondent's preferences. The author of the study conducted all interviews and speaks fluently all three languages. The Institutional Review Board of the Northern Arizona University and the Ethical Committee of the Ministry of Health and Social Protection of the Republic of Tajikistan approved the study. Each participant was provided with details of the study prior to the interview and the consent form. Oral consent was obtained and recorded on digital recorders with the permission of the respondents. The interviews were conducted face-to-face in the respondents' office (private setting) and lasted from 30 to 60 minutes. Three participants of the study refused to be recorded and the author took detailed notes during these interviews. All interviews and notes were fully transcribed verbatim in the language they were originally conducted, and then translated into English for coding and analysis purposes by the author.

Data analysis

The transcripts were analyzed using NVivo software for qualitative data analysis, Version 12 Plus, 2019 (QSR International Pty Ltd, 2019). Transcripts were read numerous times before coding them for initial codes. Codes were extracted across all transcripts. The research question directed initial coding and when new concepts emerged, they also guided the coding process. Single codes or those irrelevant to the research question were removed. The remaining codes were tested against the data to guarantee reliability of coding and face validity (i.e., that they mirror the meaning given to them by the respondents). All initial codes were examined to identify overarching themes. The emerging themes were carefully and deliberately examined. Similar factors in both research settings were used to merge them into common and atypical themes. Relevant documents were also reviewed. Careful reading of documents led to the creation of a coding template with themes and sub- themes of interest in NVivo. The coding template guided extraction of excerpts from analyzed documents and they were added to the appropriate sections of the template.

There are limitations which should be taken into consideration when considering the study findings. They include the retrospective nature of the study. The reflective nature of the interview methodology itself invites the interviewees to recall information from the past; there is, therefore, a high chance of a recall bias. The power dynamic between the interviewer and interviewee could be another limitation. Although the researcher tried to use the self-reflexivity method to avoid reproduction of inequality in the research (Naples \& Sachs, 2000). 


\section{Results}

\section{Poor and inadequate knowledge of TBAs}

Qualitative research findings in the research settings suggest that most health care providers in the present study expressed complete dislike for TBAs criticizing them of having poor, insufficient and inadequate knowledge of pregnancy and birthing practices. Study respondents argue that the TBAs' poor knowledge is a result of not receiving any special training or education on obstetric skills, practices, and services. These claims/statements were captured in the following quotes:

I am very sceptical about TBAs. I do not think that they have sufficient knowledge about birth. They do not have a medical knowledge (R12).

I have a very negative opinion about them. I asked [them] "How do you (i.e. a TBA) know that it is time for a woman to have a baby?" She [i.e. TBA] said: "When I see", showing on her finger, "that this much is left, then I know that she is about to give birth." They basically do not know anything. They did not study (i.e. study in a medical college or university) and are not aware of these aspects. She (i.e. TBA) says that it all depends on her finger. They only know by finger. They basically do not have any other anatomical or physiological knowledge about birth (R2).

According to some health professionals, the poor knowledge is the reason that TBAs are not aware of anatomical and physiological aspects of birth, stages of birth, how to properly manage the third stage of the birth, how to deliver a baby, how to manage each stage in particular, and childbirth in general as well as not being able to demonstrate an active management of the third stage of the birth. They also cannot give injections such as an oxytocin if there was a need according to study respondents. The health care workers also suggest that the poor and inadequate knowledge of TBAs about obstetric practices may potentially harm the health of new-borns.

I think they are uneducated. They do not have a special training, neither this nor that. They do not even know how to deliver a baby; how to manage the placenta (posled); and how to manage the third stage of the birth. Many new-borns can become disabled (invalid) as a result (R1).

For example, they do not know about the active management of the delivery. A midwife would prepare an injection of oxytocin for herself. She would perform a massage of uterus and this and that, but TBA will not know what a massage of uterus is, and what a management of the birth is (R2). 
Thus, one of the main findings of the present study is a significant gap in knowledge of TBAs. However, health care providers, who were all doctors of obstetrician gynaecologists, held a very positive view about midwives or nurses assisting during birth due to them having medical education/training.

I am not for this. I have never supported this. I do not support when deliveries are assisted by TBAs. Midwives, yes. Births should be assisted by midwives, those who have medical education. I do not support TBAs. It is ok for women to choose to have home delivery, but it should be attended by medical personnel (meaning SBAs) (R9).

\section{Failing to follow clean birth practices}

Health care providers also argue that TBAs had poor skills in infection control and were not aware of the importance of clean and hygienic birth practices during delivery and postnatal period. The health care workers state that they do not use clean and sterile delivery materials such as new or sterilized/disinfected scissors or cord cutting materials, clean sheets, and towels.

They [i.e. TBAs] do no use sterile material, because they simply can use any cloth that is available. I am confident that even her [TBA's] scissors are not sterile. So, there will be microbe and then infection (R3).

I do not think that they even know how to sterilize their scissors or use clean sheets or cloth during delivery, and it is a very big concern for me (R13).

Many respondents of the study also state that TBAs do not use gloves to prevent transmission of infections and fail even to protect themselves from different infections such as HIVIAIDS and hepatitis. Health care workers also argue that without adequate infection control skills, TBAs cannot prevent and manage infections, which might lead to complications in the postnatal period. Failing to follow clean birth standards/practices might also predispose the TBAs themselves to infections and could even turn them into becoming vectors for transmission. The following quotes will show this way of thinking:

They do not even wear gloves when they assist women during birth... Above all, they do not wear gloves to protect even themselves from all the infections including hepatitis, HIV, and particularly HIV (R2).

They do not follow hygienic norms even for their own safety. They often do not sterilize their material that they use during deliveries (R12). 
I am very distrustful about TBAs. I do not think that they have sufficient knowledge about birth. They do not have medical knowledge and they do not follow hygiene norms even for their own safety. They often do not sterilize the material they use during deliveries (R16).

\section{Management of complications and poor maternal health outcomes}

Health care providers interviewed for this study state that TBAs have lower professional competence due to issues such as inability to recognize early and manage obstetric complications that might be fatal for women. TBAs are not aware of standard practices to identify obstetric complications including determining whether it is a postnatal haemorrhage or a normal loss of blood after a birth. They use visual observation to identify excessive bleeding instead of using standard measurement of postnatal haemorrhage which is, as well known, dangerous. Only one health care provider despite her negative view of TBAs highlights that TBAs are only useful for emergency cases when SBAs are not available. We see these sentiments from the below quotes:

If a woman losses blood after birth, it will also lead to anaemia. I doubt whether she [i.e. a TBA] knows what the normal loss of blood is, and what is not. She would think that it is a normal blood loss after the delivery (R1).

I do not support them [i.e. TBAs]. They do not provide good quality care. I do not believe they can learn a lot from a short training that they receive if they receive any at all. However, I think in the emergency situation, it is better to have them [present during delivery] than no one. At least they know how to deliver the baby and cut cord. So, they are good only for the extreme and emergency situations when there are no other health care workers available (R16).

Some health care providers argue that TBAs are not able to provide medical assistance when complications arise during deliveries. For instance, TBAs cannot stitch tears of vagina and vulva after childbirth which leads to cystocele (when the wall between the bladder and the vagina weakens and the bladder drops from its normal position in the pelvis and pushes on the wall of the vagina) and poor maternal health outcomes. Some women who receive assistance from TBAs during their delivery would later need genital surgery. Many health care providers highlight that the use of TBAs has a negative impact on the maternal health of women in Tajikistan.

They do not know how to manage the third stage of delivery - the placenta management. For example, when a piece of placenta retains in the uterus, they do not know how to manually remove it. They also cannot inject oxytocin. They are also not able to stitch the tears during deliveries. Women come and their vaginas are ripped and were not stitched properly. Their vaginas look so bad, and these women then need to have genital surgeries. This also results in poor maternal health (R3). 
I do not support when nonmedical personnel deliver births. It already impacts maternal health. If a woman has vaginal tears, she will then develop cystocele, and later other complications. Then when a woman comes [to us], her anus and vagina are interconnected. She will lose all her health (R9).

\section{Rare positive perspectives}

Only few health care providers expressed positive view about the use of TBAs during childbirth. One of them states that if she encounters delays in reaching a woman to assist a childbirth at home and by the time, she arrives a TBA has already assisted the woman, it leads to good results.

I think they do well. Sometimes, people ask me to come to assist with the birth. By the time I arrive, I see TBAs already delivered the baby, cleaned her spot, and the woman does not have any tear after birth. I think it is normal. Those who are traditional birth attendants (pirzecha) are quite good (R4).

Despite very negative views about TBAs, two other respondents appreciate that they avoid using unnecessary medical interventions during delivery. They even compare their management of a childbirth with the one that WHO recommends at present. In particular, health workers highlight WHO advocacy for a minimum use of medical interventions during delivery.

On the one hand, they do not touch the woman unnecessarily - this is the only advantage of giving birth with TBAs. The most ancient traditional birth attendants did not intervene so much in the physiological process of birth. They do not touch unnecessary women without any need...... Birth therefore unfolds as a physiological process without a medical intervention. But she [i.e. a TBAs] also does not do anything about the placenta (R2).

Yes, there are some old women who assist women during deliveries in some places. Do you know that their methods (metodika) are quite ancient? It is very similar to the one used during the standard management of delivery protocols. It is almost the basis of the standard management of delivery. The only aspects missing are the use of oxytocin and placenta management. They manage complications that is called [locally] ar poth thod [i.e. when baby is in oblique position] very well (R3). 


\section{DISCUSSION}

Most of the existing literature devoted to the study of TBAs focus on their perspectives regarding their knowledge and practices although they are set in very diverse research settings. However, insights of the health care professionals about the knowledge and practices of the TBAs have not been adequately explored. This paper explores the view of health care workers on TBAs' knowledge and practices and therefore not only opens new avenues in the study of this subject, but also can potentially improve our understanding of this very important topic.

A strong critique of TBAs and negative viewpoint about their knowledge and training among the health care workers interviewed for this study are among the main findings of the current study. A thorough analysis of responses of health care workers shows that such a viewpoint is mainly based on the poor and inadequate knowledge of TBAs in terms of different anatomical and physiological aspects of birth. The Tajik health care workers consider TBAs' knowledge as insufficient to safely manage births. This finding is in line with Kruske and Barklay (2004) who also state that the TBAs' knowledge, including those who were instructed by health care workers, was considered as inferior and did not have professional eminence. A study in Tanzania also shows that most TBAs did not possess comprehensive bio-medical proficiencies, skills, and resources (Pfeiffer \& Mwaipopo, 2013).

Health care providers in the present study connect the poor knowledge of TBAs with the fact that the latter do not receive any special training or education on obstetric skills and services. Similar to the findings of the current research, several studies have also reported that TBAs receive negligible training and education and, even those who receive, training, require the assistance of skilled health care services (Adatara et al., 2018). The study in Ghana emphasizes that while TBAs have not been officially educated to assist births, they have been helping women deliver their babies at home for years (Adatara et al., 2018). The finding in Ghana resonates with the situation in Tajikistan, where TBAs without any or some training on obstetrics also assist women yet they lack knowledge of different aspects of childbirth.

Lack of knowledge of TBAs is an important finding that needs to be explored further in future research studies in the Tajik context. However, a future study should be conducted not only among health care providers but also among the TBAs. The inclusion of TBAs in the future studies in the context of Tajikistan will help show the real knowledge of TBAs and also might address the possible biases of health professionals against TBAs.

The present study also found that the study respondents have a negative point of view about the TBAs because of their use of unsafe practices. The health care providers in the current study argue that TBAs had poor skills in infection control and did not follow clean delivery practices during childbirth. Tajik health workers claim that TBAs do not use clean cord-cutting instruments, clean sheets, and towels to prevent infection in women and newborns. Moreover, TBAs were also blamed for not using gloves to prevent transmission of infections to women or to protect themselves. This was also reported by Pfeiffer 
and Mwaipopo (2013) who found that safety principles and hygiene measures are seldom upheld by TBAs in Tanzania. TBAs were accused of unsafe practices in a study in Uganda as well (Chi \& Urdal, 2018). Aziato and Omenyo (2018) highlight that TBAs rarely use gloves during their assessments (for example, to assess cervical dilatation and the amniotic membranes) or delivery thus increasing the risk of transmitting infections significantly and might lead to the introduction of bacteria from the vagina to the fetus (chorioamnionitis). The TBAs might also assist more than one pregnant woman at a time, they could therefore consequently transmit infections from woman to woman (Aziato \& Omenyo, 2018). This is a significant concern in the era of HIV and AIDS (Aziato \& Omenyo, 2018; Pfeiffer \& Mwaipopo, 2013). The concern about transmission of HIV between pregnant women and TBAs who assist their birth and poor infection control measures were among the main reasons behind the prohibition of the use of TBAs in other research settings (Chi \& Urdal, 2018).

These unsafe, unhealthy and risky practices can harm the health of Tajik women and need to be addressed to improve maternal and newborn health in Tajikistan. The Tajik government needs to provide an SBA in each remote rural area in the near future. This can be done by addressing disparities in the availability of health care workers across the different regions and geographical locations in Tajikistan. Tajikistan has a large number of doctors and other health care workers, but their geographic distribution varies considerably, and they are mainly concentrated in the cities, while there is a deficit of doctors and nurses in remote rural areas (Mirzoev et al., 2007; Parfitt \& Cornish, 2007). For instance, the number of doctors is much higher; in Dushanbe, at 71 per 10,000, than in the whole country (Fan \& Habibov, 2009; Mirzoev et al., 2007). Unlike other countries of the Global South, it is not a lack of health professionals but misdistribution of health care workers that Tajikistan is suffering from. The government should tackle disparities of health care workers by using different strategies such as providing incentives to health care professionals to work in places which lack ones.

It is within this context that one of the main arguments of this paper also emerges. It is important to draw a clear distinction between the various countries of the Global South or the so-called Third World - regardless of the term we use - without brushing the condition and health indicators of these countries with one paint. The historical circumstances of Tajikistan and other Central Asian countries of the postSoviet sphere means that their health care system cannot be even likened or compared to that of the many countries of Africa, Latin America, South and Southeast Asia. These are countries which, at one point in the late 1980s, had access to a comparatively well-functioning primary and secondary health care systems and benefited from highly trained and large numbers of nurses and doctors. Moreover, the health care system was universal and free. The mistake that many studies make when talking about the health care system in the post-Soviet countries of Central Asia therefore is that they use the same language and images that they would use to describe the health care systems and provisions in the countries that never saw a health care system that was universal, free and of good quality. 
There are of course similarities between the various systems of the Global South countries, such as in the case of the use of TBAs, but that similarity mainly ensues from the geographical terrain of these countries and the issues of accessibility rather than the lack of doctors and nurses, and the notion of how a health care system is meant to function. Therefore, one would find, for example, that similar to the midwives in the study of Gurara et al. (2019) in Ethiopia, the Tajik health care providers also argue that TBAs do not contribute to the improvement of maternal health. Chi and Urdal (2018) discuss the critique of TBAs' involvement in delivery by health care workers of the official health care system in Burundi and Uganda. Health care workers state that TBAs practices result in various complications such as injuries to vagina and vulva requiring further genital cosmetic surgeries. Their practices also lead to different kinds of newborn disabilities. Tajik health care providers also believe that TBAs are woefully unprepared to determine complications (e.g. determining blood loss) during delivery. The criticism regarding TBAs' practices by health care professionals are not limited to Tajikistan.

A study in Nepal also found that the TBAs were required to use an official methodology to measure postnatal blood loss after it was revealed that $83 \%$ of TBAs mentioned that they recognized excessive bleeding "by seeing it" (Falle et al., 2009, p. 58). However, early detection and correct assessment of blood loss are essential factors for managing postpartum bleeding and saving the life of a woman (Walraven \& Weeks, 1999). Thatte et al. (2009) also highlight that improving the recognition of signs of danger, including excessive hemorrhage, and defining the optimum response, can ensure the survival of both woman and newborn. A study from Tanzania also show that two kanga (standard-size cotton cloth used by women in East Africa) soaked in blood represented loss of slightly more than $500 \mathrm{ml}$ of blood and used this threshold in training of TBAs (Thatte et al., 2009). Calculating the number of pieces of fabric soaked with blood or utilizing a blood collection drape to estimate excessive loss of blood are better than visual measures and can be promising strategies (Thatte et al., 2009). Underestimation of blood loss and postnatal bleeding are the most important factor in maternal mortality (Walraven \& Weeks, 1999). Therefore, an analogous measurement tool (e.g. using cotton cloth) should be a part of the midwives training for emergency situations, but the emphasis should be on the official methodology of measuring postnatal blood as part of training of midwives in Tajikistan. I think training midwives and preparing them for assisting women in situations and conditions where sophisticated tools are not available is crucial.

The perspectives of health care providers in terms of knowledge and practices of TBAs show that the TBAs put the health of Tajik women at risk. It is therefore necessary that in the near future the Tajik government should provide SBAs in all remote rural areas that lack one currently. Indeed, the ideal solution for improving maternal and neonatal health outcomes is recruiting midwives for remote rural areas. In Tajikistan, some urban, sub-urban and even rural areas have actually excessive number of health professionals (Mirzoev et al., 2007), there is a need to identify areas where TBAs are the only help that Tajik women can rely on and replace them gradually with SBAs with a basic incentive arrangement (Chi \& Urdal, 2018). These changes are not difficult to implement, and they should not require huge sums, because unlike other countries of the Global South, majority of places in Tajikistan 
have SBAs including urban and sub-urban areas which actually have excessive number of them. Although there is still a high number of health professionals due to a legacy of the USSR when higher education was free, and the problem is addressing the misdistribution of health professionals. However, in the future, taking into account that an increasing number of educational institutions require students to pay for their education now, and there might be a lack of health care workers in the future, Tajikistan has to train purposefully midwifes who would be willing to stay and work in rural settings and it should be a national priority (Srofenyoh et al., 2016). Homogeneous approach should be avoided while studying and addressing health issues in the countries of the Global South because due to different socio-economic, political and historical factors, situations and environments in these countries might be different. Therefore, it is absolutely crucial to avoid a homogeneous public health approach while tackling health problems in different parts of the world. It is important to use a unique, and culturally and locally appropriate strategy to effectively address public health issues in countries of the Global South. Tajikistan is on the right track and is currently quite successful in reducing its MMR unlike the United States. Providing SBAs for all its geographical settings which the Tajik government can achieve by redistributing health care workers, and addressing the misdistribution of health professionals in Tajikistan. This approach might also be helpful in other post-Soviet countries in the Central Asia or Caucasus.

\section{CONCLUSION}

The study shows that health care professionals have extremely negative views of the use of TBAs during childbirth citing their lack of medical training and knowledge, and their lax attitude towards hygiene and clean birth practices as main reasons. Most health care providers believe that TBAs should be banned from practicing. They argue that TBAs put the lives of Tajik women at risk. Health care workers also argue that TBAs are doing more harm than good and therefore should be replaced by SBAs.

Analysis of the literature on the subject has revealed that very often a homogeneous and unilateral approach has been applied to different countries regardless of their socio-economic, historical and structural factors by global public health experts. However, it is important that we use an approach that is locally, structurally and culturally appropriate to address health issues in different countries of the Global South taking these important aspects into consideration instead. Tajikistan, as a country, can solve the issue of using TBAs by rectifying the way in which the health care sector and its staffing is organized. As mentioned, Tajikistan has an excessive number of health care workers, but they are distributed unequally throughout the country. The government could be able to solve the issue of the lack of maternal health care in some of its remote regions by addressing the misdistribution of health professionals throughout the country. 
The presence of an SBA at childbirth is crucial for averting maternal and neonatal mortality and morbidity and is the ideal that any health care system should strive towards in those countries of the Global South that have this opportunity. Granted that it is possible to achieve this easily in some countries of the Global South, it should be promoted and implemented. Tajikistan is on the right track and is currently quite successful in reducing its MMR. At the same time, providing SBAs in these remote rural areas could further decrease its MMR indicator. The study, therefore, might benefit the field by filling the gap in the existing literature on TBAs by providing health care workers' perspectives. This will in turn, help to design comprehensive and systematic reproductive health programs to improve the maternal health of Tajik women taking into account specificities of this country and other post-soviet countries in the Central Asia. One important aspect of such a program can be finding ways to improve the maternal and neonatal health by providing SBAs in rural areas to assist the most marginalized Tajik women during delivery which the Tajik government can do by managing its resources properly.

\section{Conflicts of Interest}

The author declares no conflicts of interest.

\section{Funding}

This research was supported in part by a grant from the College of Social and Behavioral Sciences' research support program, the Northern Arizona University.

\section{References}

- Adatara, P., Afaya, A., Baku, E.A., Salia, S. M., \& Asempath, A. (2018). Perspective of traditional birth attendants on their experiences and roles in maternal health care in rural areas of Northern Ghana. International Journal of Reproductive Medicine, 11, 1-10. DOI: 10.1016/j.jmwh.2004.01.005.

- Aziato, L., \& Omenyo, C.N. (2018). Initiation of traditional birth attendants and their traditional and spiritual practices during pregnancy and childbirth in Ghana. BMC Pregnancy and Childbirth, 18, 64. https://doi.org/10.1186/s12884-018-1691-7.

- Balabanova, D., McKee, M., Pomerleau, J., Rose, R., \& Haerpfer,C. (2004) .Health service utilization in the former Soviet Union: Evidence from eight countries. Health Services Research, 39,1927-1950. doi: 10.1111/j.1475-6773.2004.00326.x.

- Baranov, A.A. (1991). Maternal and child health problems in the USSR. Archives of Disease in Childhood, 66, 542-545. doi: 10.1136/adc.66.4.542.

- Chi, P.C., \& Urdal, H. (2018). The evolving role of traditional birth attendants in maternal health in post-conflict Africa: A qualitative study of Burundi and Northern Uganda. SAGE Open Medicine, 6, 1-9. doi: 10.1177/2050312117753631.

- Choguya, N.Z. (2014). Traditional birth attendants and policy ambivalence in Zimbabwe. Journal of Anthropology, 2. https://doi.org/10.1155/2014/750240.

- Fan, L., \& Habibov, N.N. (2009). Determinants of accessibility and affordability of health care in post-socialist Tajikistan: Evidence and policy options. Global Public Health, 4, 561-574. doi: 10.1080/17441690802128297.

- Falkingham, J. (2003). Inequality and changes in women's use of maternal health-care services in Tajikistan. Studies in Family Planning, 34, 32-43. doi: 10.1111/j.1728-4465.2003.00032.x.

- Falle, T.Y., Mullany, L.C., Thatte, N., Khatry, S.K., LeClerq, S.C., Darmstadt, G.L., Katz, J., \& Tielsch, J.M. (2009). Potential role of traditional birth attendants in neonatal healthcare in rural Southern Nepal. Journal of Health, Population and Nutrition, 27, 53-61. doi: 10.3329/jhpn.v27i1.3317. 
- Gurara, M., Muyldermans, K., Jacquemyn, Y., Van Geertruyden, J., \& Draulans, V. (2019). Traditional birth attendants' roles and homebirth choices in Ethiopia: A qualitative study. Women and Birth 33: e464-e472. doi: 10.1016/j.wombi.2019.09.004. Epub 2019 Nov 4.

- Habibov, N.N., \& Fan, L. (2008). Modelling prenatal health care utilization in Tajikistan using a two-stage approach: Implications for policy and research. Health Policy and Planning, 23, 443451. DOI: $10.1093 /$ heapol/czn032.

- Hernandez, S., Oliveira, J.B., \& Shirazian, T. (2017). How a training program is transforming the role of traditional birth attendants from cultural practitioners to unique health-care providers: A community case study in rural Guatemala. Frontiers in Public Health, 5, 111. DOI: 10.3389/fpubh.2017.00111.

- Hobday, K., Hulme, J., Homer, C., Zulato Wate, P., Belton, S., \& Prata, N. (2018). My job is to get pregnant women to the hospital: A qualitative study of the role of traditional birth attendants in the distribution of misoprostol to prevent post-partum haemorrhage in two provinces. Reproductive Health, 15, 174. doi: 10.1186/s12978-018-0622-4.

- Kruske, S., \& Barclay, L. (2004). Effect of shifting policies on traditional birth attendant training. Journal of Midwifery \& Women's Health, 49, 306-311. doi: 10.1016/j.jmwh.2004.01.005.

- Lane, K., \& Garrod, J. (2016). The return of the traditional birth attendant. Journal of Global Health, 6, 2. doi: 10.7189/jogh.06.020302.

- Mirzoev, T., Green, A., \& Newell, J. (2010). Health SWAps and external aid - a case study from Tajikistan. International Journal of Health Planning and Management, 25, 270-286. DOI: $10.1002 / \mathrm{hpm} .971$.

- Miskinzod, D. (2020). Maternal mortality in Tajikistan: Successes and challenges. International Journal of Women's Health and Wellness, 6, 111. DOI: $10.23937 / 2474-1353 / 1510111$.

- Naples, N.A., \& Sachs,C. (2000). Standpoint epistemology and the uses of self-reflection in feminist ethnography: Lessons for rural sociology. Rural Sociology, 65, 194-214. https://doi.org/10.1111/j.1549-0831.2000.tb00025.x.

- Parfitt, B.A., \& Cornish, F. (2007). Implementing family health nursing in Tajikistan: From policy to practice in primary health care reform. Social Science \& Medicine, 65, 1720-1729. doi: 10.1016/j.socscimed.2007.06.007.

- Patzer, C. (2021, March 23). Scaling up midwives and traditional birth attendants to reduce maternal mortality: Recommendations for policymakers \& program managers. https://www.wilsoncenter.org/event/scaling-midwives-and-traditional-birth-attendants-toreduce-maternal-mortality-recommendations.

- Pyone, C., Adaji, S., Madaj, B., Woldetsadik, T., \& van den Broek, N. (2014). Changing the role of the traditional birth attendant in Somaliland. International Journal of Gynecology and Obstetrics, 127, 41-46. doi: 10.1016/j.ijgo.2014.04.009.

- Pfeiffer, C., \& Mwaipopo, R. (2013). Delivering at home or in a health facility? Health-seeking behaviour of women and the role of traditional birth attendants in Tanzania. BMC Pregnancy and Childbirth, 13, 55. https://doi.org/10.1186/1471-2393-13-55.

- QSR International Pty Ltd. (2019). NVivo 12 Plus for Windows (Version 12). https://www.qsrinternational.com/nvivo/nvivo-products/nvivo-12-plus

- Republican Medical Statistical Center under the Ministry of Health and Social Protection of the Republic of Tajikistan (RMSC). (2018). Maternal mortality, 2008-2017. Dushanbe: RMSC.

- Skinnider, M. (2000). Dispatches from abroad: Fighting maternal mortality in a former Soviet Republic. Canadian Medical Association Journal, 163, 1605. https://www.ncbi.nlm.nih.gov/pmc/articles/PMC80601/pdf/20001212s00030p1605.pdf

- Srofenyoh, E.K., Kassebaum, N.J., Goodman, D.M., Olufolabi, A.J., \& Owen, M.D. (2016). Measuring the impact of a quality improvement collaboration to decrease maternal mortality in a Ghanaian regional hospital. International Journal of Gynaecology \& Obstetrics, 134, 181-185. DOI:10.1016/j.ijgo.2015.11.026.

- Statistical Agency under the President of the Republic of Tajikistan [SAPRT], the Ministry of Health of the Republic of Tajikistan [MHRT], \& ICF International (SAPRT, MHRT \& ICF International). (2013). Tajikistan Demographic and Health Survey 2012. https://dhsprogram.com/publications/publication-fr279-dhs-final-reports.cfm

- Thatte, N., Mullany, L.C., Khatry, S.K., Katz, J., Tielsch, J. M., \& Darmstadt, G.L. (2009). Traditional birth attendants in rural Nepal: Knowledge, attitudes, and practices about maternal and newborn health. Global Public Health, 4, 600-617. doi: 10.1080/17441690802472406..

- Walraven, G., \& Weeks, A. (1999). The role of (traditional) birth attendants with midwifery skills 
in the reduction of maternal mortality. Tropical Medicine and International Health, 4, 527-529. DOI: 10.1046/j.1365-3156.1999.00441.x.

- Wiegers, T.A., Boerma, W.G.W., de Haan, O. (2010). Maternity care and birth preparedness in rural Kyrgyzstan and Tajikistan. Sexual \& Reproductive Health, 1, 189-194. doi: 10.1016/j.srhc.2010.08.004.

- World Health Organization (WHO). (1992). Traditional birth attendants: A joint WHO/ UNFPA/UNICEF statement. https://apps.who.int/iris/handle/10665/38994

- World Health Organization (WHO). (2014). Trends in maternal mortality 1990-2013. https://www.unfpa.org/sites/default/files/pub-pdf/9789241507226_eng.pdf 